\title{
PRODUCTION OF MONOCLONAL ANTIBODY TO QUANTIFY SERUM CA125 CONCENTRATION IN BREAST AND OVARIAN CANCER PATIENTS
}

\author{
Nguyen Thi Xuan ${ }^{1,2, *}$, Nguyen Trong $\mathrm{Ha}^{3}$ \\ ${ }^{1}$ Institute of Genome Research, VAST, Vietnam \\ ${ }^{2}$ Graduate University of Science and Technology, VAST, Vietnam \\ ${ }^{3} 103$ Hospital, Vietnam Military Medical University, Ha Noi, Vietnam
}

Received 27 May 2020, accepted 20 September 2020

\begin{abstract}
Ovarian carcinoma (OC) and breast cancer (BC) are mainly caused by alterations in genes such as $B R C A 1$ and $B R C A 2$, which are involved in differentiation and survival of cancer cells. The protein CA125 (MUC16) is released by cancer cells in most OC and a few BC patients. The cutoff point of CA125 level for tumor growth and metastasis is $35 \mathrm{U} / \mathrm{mL}$. Production of CA125 monoclonal antidody (mAb) to determine expression level of this antigen by ELISA has been well known. In this study, we aimed to generate CA125-specific mAb for developing a new inhouse ELISA kit. To this end, BALB/c mice were immunized with CA125 protein and splenocytes of immunized mice were fused with myeloma Sp2/0 cells. Efficiency of mAbs secreted from the hybridoma clones was examined by ELISA and flow cytometry analysis. As a result, among 3 stable hybridoma cell lines identified, A1 clone attained about $90 \%$ positive for anti-CA125 mAb, whereas $\mathrm{H} 1$ and $\mathrm{H} 3$ clones were about $40 \%$ and $50 \%$ positive for anti-CA125 $\mathrm{mAb}$, respectively. By flow cytometry analysis, anti-CA125 mAb from A1 clone was more specific to CA125 antigen present in OVCAR -3 cells than those from $\mathrm{H} 1$ or $\mathrm{H} 3$ clone. In addition, the isotype of the obtained mAb was specific IgG1 and Kappa light chain. In conclusion, the mouse anti-human CA125 mAb generated in our lab was specifically binding to CA125 antigen and used as the capture antibody in sandwich ELISA system for early diagnosis as well as monitoring therapeutic response in OC patients.
\end{abstract}

Keywords: CA-125, breast cancer, ELISA, ovarian cancer, monoclonal antibodies.

Citation: Nguyen Thi Xuan, Nguyen Trong Ha, 2020. Production of monoclonal antibody to quantify serum CA125 concentration in breast and ovarian cancer patients. Academia Journal of Biology, 42(4): 109-116. https://doi.org/10.15625/2615-9023/v42n4.15095

*Corresponding author email: xuannt@igr.ac.vn

(O2020 Vietnam Academy of Science and Technology (VAST) 


\section{INTRODUCTION}

Ovarian carcinoma (OC) is the seventh most common cancer in women worldwide, with a 5-year survival rate of only $30 \%$ due to most OC patients being diagnosed at an advanced stage of the disease (Coward et al., 2015). Breast cancer (BC) is the main cause of cancer death among women aged 40-55 worldwide. Most patients with $\mathrm{BC}$ are 50 and older, however, approximately $6-7 \%$ of young $\mathrm{BC}$ patients are $\leq 40$ years (Libson et al., 2014). Studies on both cancers indicated that alterations in the genes BRCAl and $B R C A 2$ are involved in differentiation and survival of cancer cells, which are the main cause of hereditary OC and BC syndrome (Ford et al., 1998). Besides, activation of multiple cell signalling pathways in $\mathrm{OC}$ and BC cells (Reinartz et al., 2012) leads to the release of a number of tumor-associated antigens such as cancer antigen 125 (CA125, mucin 16, MUC16). Therefore, the level of this antigen is enhanced in most $\mathrm{OC}$ and a few $\mathrm{BC}$ patients.

MUC16 consists of a C-terminal domain containing a short cytoplasmic tail, a transmembrane domain and an N-terminal, highly glycosylated extracellular domain (O'Brien et al., 2001). The cut-off point of CA125 level for tumor growth and metastasis is $35 \mathrm{U} / \mathrm{mL}$ (Felder et al., 2014). CA125 is used for prognosis and controlling of therapeutic effect in OC, however its sensitivity is low in the early stages of disease (about 50\% of patients) (Felder et al., 2014). When the elevated content of serum CA125 in OC patients is persistent after three cycles of chemotherapy, it implies progressive malignant disease and poor therapeutic response (Bottoni et al., 2015). CA125 concentration is also correlated directly with disease stage and inversely with survival in OC patients (McIntosh et al., 2004). Activations of innate immune cells, including natural killer (NK) cells and monocytes, do not affect tumor cells expressing high level of CA125, therefore, inactivation of CA125 leads to increased lysis of the OC cells by the cytolytic NK cells (Felder et al., 2014) and inhibits proliferation of cancer cells through STAT3 via JAK2 signalling (Senapati et al., 2010). CA125 is also used for early diagnosis of $\mathrm{BC}$ and $\mathrm{OC}$ in families with $B R C A$ mutations (Vasen et al., 2005). In BC patients, enhanced expressions of CA125, CA15-3 and CEA markers are related to the pathogensis of the disease (Zhao et al., 2016), in which CA125 provides predictive information in the course of BC (Zhao et al., 2016). CA125 is not infrequently elevated in patients with benign breast and ovarian tumors and several studies have shown that deviations in CA 125 may occur 18 months or more before clinical diagnosis (McIntosh et al., 2004).

To quantify CA 125 concentration in sera of cancer patients or cell supernatants by enzyme-linked immunosorbent assay (ELISA), anti-CA125 monoclonal antibody $(\mathrm{mAb})$ is used as the capture or detection reagent in the development of sensitive ELISA assays. Immunization-hybridoma technology is one of the most prominent method for generating MAbs, which are known as precise instruments used in medical research, diagnosis, and treatment of diseases (Kohler et al., 1992). MAbs are secreted from a single clone of lymphocyte $\mathrm{B}$ based on fusion between myeloma cells such as P3X63Ag8.653, Sp2/0-Ag14, NS1, and NS0 (Yoo et al., 2002) and splenocytes from suitably immunized animals. The hybridoma cell line displays the property of immortality of the tumor cell with the specificity of the original B lymphocyte (Kohler et al., 1975).

In this study, we developed a mAb against CA125 to be used as a capture antibody in ELISA technique for detecting CA125 concentration in sera of $\mathrm{OC}$ and $\mathrm{BC}$ patients. The results of CA125 level in this study were compared with that performed using a commercial CA125 ELISA kit.

\section{MATERIALS AND METHODS}

\section{Patients and control subjects}

Fresh peripheral blood samples were collected from 29 untreated adult patients aged from 40-65 years who were diagnosed with OC (13 patients) and BC (16 patients) 
based on immunohistochemistry results and clinical outcomes obtained from a review of medical records, at the 103 Military Hospital, Hanoi, Vietnam. No individuals in the control population took any medication or suffered from any known acute or chronic disease. All patients gave a written consent to participate in the study. Individual care and experimental procedures were performed according to the Vietnamese law for the welfare of human and were approved by the Ethical Committee of Institute of Genome Research, Vietnam Academy of Science and Technology.

\section{Cell culture}

Ovarian carcinoma cell line (OVCAR-3) was obtained from American Tissue Type Culture (ATCC). Cells were seeded $\left(2 \times 10^{6}\right)$ into T-75 flasks (Corning Costar) and propagated to confluence (4-5 days) in $15 \mathrm{ml}$ RPMI-1640 medium (Gibco) supplemented with $10 \%$ heat-inactivated fetal bovine serum (FBS, Thermo), $10 \mathrm{mg} / \mathrm{ml}$ insulin, and $1 \%$ penicillin/streptomycin solution (Gibco). Mouse myeloma SP2/0 cell line was purchased from Sigma Aldrich and propagated in RPMI1640 containing $10 \%$ FBS, $1 \%$ penicillin/streptomycin solution, and 0.25 $\mathrm{mg} / \mathrm{mL}$ amphotericin B (Sigma-Aldrich). All cells were cultured in an incubator at $37{ }^{\circ} \mathrm{C}$ with $5 \% \mathrm{CO}_{2}$.

\section{Isolation of peripheral blood mononuclear cells (PBMCs)}

PBMCs from whole blood samples of healthy donors were collected by venipuncture and transferred to sterile tubes containing EDTA as anticoagulant. The cells were isolated via density gradient centrifugation (Ficoll-Paque Plus, GE Healthcare Life Sciences) using Hank's buffer (Gibco). Freshly isolated PBMCs were obtained by centrifuging at $400 \mathrm{~g}$ for $30 \mathrm{~min}$ at room temperature. The cells were counted in a Neubauer chamber and washed with PBS, the final cell pellet was resuspended in PBS and stained with Abs for flow cytometry. Most ( $80 \%$ or more) of the cells were negative with PI staining.

\section{Mouse immunization and screening of immunized mice}

Two female BALB/c (6-8 weeks old, Hudson, NY, USA) mice were subcutaneously immunized with $50 \mu \mathrm{g}$ of purified human CA125 protein (Fitzgerald Industries) per injection with Freund's complete adjuvant (Sigma) for the first dose using an emulsifier syringe. A booster injection was given 10 days later with CA125 protein (Thermo) emulsified with incomplete Freund adjuvant (Thermo) and followed by a similar booster injection 2 weeks later. Venous blood was obtained from the tail of the immunized mice 7 days after the second booster vaccination.

\section{ELISA screening}

Mouse serum titrations and screening of hybridoma cell supernatants were performed by ELISA. CA125 protein $(10 \mu \mathrm{g} / \mathrm{mL})$ was coated with coating buffer $(50 \mathrm{mM}$ natricarbonate/bicarbonate buffer, $\mathrm{pH}=9.5)$ in microtiter plates (Corning Costar) for $1 \mathrm{~h}$ at $37{ }^{\circ} \mathrm{C}$. The wells were then washed 3 times with PBS containing $0.05 \%$ Tween 20 (PBST) for 5 min. PBS containing 2\% skim milk (200 $\mu \mathrm{l})$ was added to each well to block further binding sites. Dilution of commercial antibody (100 $\mu \mathrm{l})$ using a 1:1000 dilution of rabbit anti-CA125 mAb (Thermo) was then added to each well, and the mixure was incubated for 2 hours at $37{ }^{\circ} \mathrm{C}$ with shaking. The wells were then washed 3 times with PBST. Horseradish peroxidase-conjugated mouse anti-rabbit IgG (Thermo) was diluted 1:5,000 in PBST containing 2\% skim milk, and $100 \mu \mathrm{l}$ were then added to each well. After $1 \mathrm{~h}$ of incubation, the wells were washed with PBST and $100 \mu \mathrm{l}$ of 3', 5'tetramethyl benzidine (TMB, Thermo) was added. After $0.5 \mathrm{~h}$ of incubation, the reaction was terminated by the addition of $\mathrm{H}_{2} \mathrm{SO}_{4} 2 \mathrm{~N}$ solution. Finally, the optical density was determined by ELISA reader.

\section{Cell fusion and hybridoma production}

The mouse with the highest serum antibody titer was selected as the spleen donor, which was aseptically removed. 
Erythrocytes were lysed with erythrocyte lysis buffer. Approximately $2 \times 10^{8}$ spleen cells were fused with $2 \times 10^{7} \mathrm{Sp} 2 / 0$ murine myeloma cells by treatment with polyethylene glycol (PEG, Sigma Aldrich) as fusogen. Fused cells were dispersed into a 24-well plate (Corning Costar) containing feeder cells $\left(10^{7} / \mathrm{ml}\right)$ and grown in hypoxanthineaminopterin-thymidine (HAT) medium (Gibco) containing 20\% FBS, $1 \%$ HAT and $1 \%$ penicillin/streptomycin. The cells were incubated at $37{ }^{\circ} \mathrm{C}$ with $5 \% \mathrm{CO}_{2}$. The media of the wells were changed at $3^{\text {rd }}$, $5^{\text {th }}, 7^{\text {th }}$ and $9^{\text {th }}$ days after fusion. Positive clones were observed at 10 days after fusion by ELISA. When hybridoma clones occupied about more than half of each well, hybridoma supernatants were initially screened by ELISA against the CA125 antigen. Positive clones were subcloned three times to obtain clones with stable production. Hybridoma cells were considered stable when the supernatants of $80-100 \%$ of wells were positive by ELISA and flow cytometry.

\section{Isotype determination}

The class and subclass of the selected CA125 mAb were identified by ELISA using mouse monoclonal sub-isotyping kit (Thermo) containing rabbit anti-mouse IgG1, IgG2a, IgG2b, IgG3, IgA, and IgM, Kappa, and lambda light chain, according to the manufacturer's instruction. Briefly, capture antibodies in the coating buffer were coated in the wells and incubated overnight at $4{ }^{\circ} \mathrm{C}$. After blocking, culture supernatant of the selected clone was added to each well for 2 hours. Then, the plate was washed and HRP conjugated anti-rabbit Ig (Thermo) added as detection antibody for 1 hour. Finally, the reactivity of the wells was measured by adding TMB (Thermo) and $\mathrm{H}_{2} \mathrm{SO}_{4} \quad 2 \mathrm{~N}$ solutions and optical density (OD) was read at $450 \mathrm{~nm}$.

\section{Antibody purification}

The CA125 mAb from cell supernatant were precipitated at $50 \%$ ammonium sulfate saturation. Precipitated proteins were dissolved and dialyzed against PBS. The final solution was transferred into the protein A affinity chromatography column. The column was washed with phosphate buffer $(20 \mathrm{mM}$, $\mathrm{pH}$ 7.2) for the absorbance to reach the background level. The bound antibody were eluted using a $0.1 \mathrm{M}$ citric acid $(\mathrm{pH} 3)$, neutralized with $1.0 \mathrm{M}$ Tris- $\mathrm{HCl}$, and then redialyzed against PBS. The concentration of purified antibody was measured using the Bradford assay (Thermo).

\section{Flow cytometry}

The positive binding of CA125 mAbs from supernatants of selected hybridoma cells to OVCAR-3 cells was detemined by flow cytometry method. The cells were stained with selected CA125 mAbs (eBiosciense) as the primary antibody at final concentration of $1 \mu \mathrm{g} / \mathrm{ml}$ for 30 minutes at $4{ }^{\circ} \mathrm{C}$. After washing twice with PBS containing 0,1\% FBS, FITCconjugated rabbit anti-mouse IgG (eBioscience) was added to the cells and incubated for further 45 minutes in the dark at $4{ }^{\circ} \mathrm{C}$. Finally, the cells were twice washed with PBS containing $0,1 \%$ FBS and expression of CA125 was assessed with FACSAria Fusion (BD Biosciences) and analyzed using FlowJo software.

\section{Statistics}

Data are provided as means $\pm \mathrm{SEM}, n$ represents the number of independent experiments. Differences were tested for significance using Student's unpaired twotailed $t$-test or ANOVA, when appropriate. $P$ $<0.05$ was considered statistically significant.

\section{RESULTS}

\section{ELISA}

Screening of immunized mice by

The titers of antibodies against CA125 protein in the sera of immunized mice showed that both mice were immunized against this antigen. As shown in Fig. 1, the antigenspecific signals were positive for both immunized mice and the sera of the two mice were titrated from 1:100 to 1:20,000. At a dilution of 1:3200, the CA125 mAb recognized the antigen, as the $\mathrm{OD}$ at this dilution was 0.75 , which is sufficient to move to cell fusion step. 


\begin{tabular}{|c|c|}
\multicolumn{2}{c}{ A } \\
\hline Dilution & Mean optical density \\
\hline IgG1 & $1.8325 \pm 0.04$ \\
\hline IgG2a & $0.1525 \pm 0.003$ \\
\hline IgG2b & $0.1705 \pm 0.001$ \\
\hline IgG3 & $0.147 \pm 0.002$ \\
\hline IgA & $0.163 \pm 0.004$ \\
\hline IgM & $0.173 \pm 0.002$ \\
\hline Kappa & $1.783 \pm 0.0037$ \\
\hline Lambda & $0.1745 \pm 0.0005$ \\
\hline
\end{tabular}

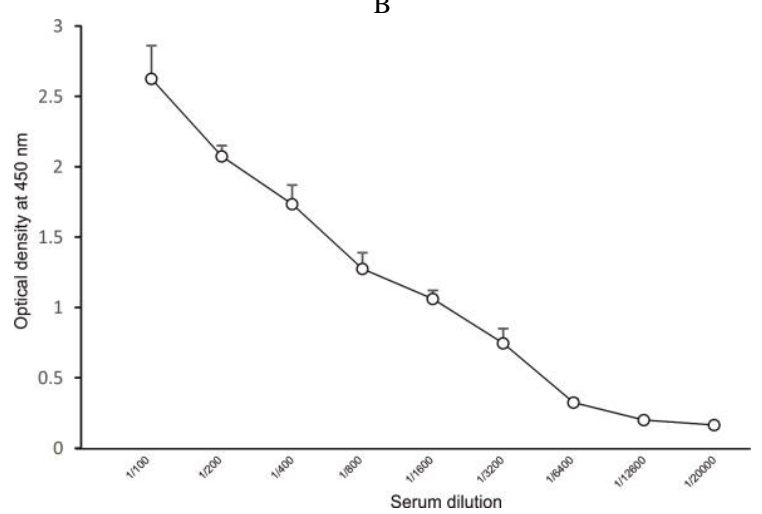

Figure 1. Serum titration after immunization against CA125 antigen. The sera from two mice were titrated in dilutions from 1:100 till 1:20.000 and tested for antigen specificity by ELISA

\section{Production of hybridoma cells}

To examine the specificity anti-CA125 mAbs secreted from hybridoma clones, ELISA plates were coated with CA125 antigen (10 $\mu \mathrm{g} / \mathrm{mL}$ ) and assessed by ELISA. Skim milk was used as negative control. We observed that $(55 / 124) 44.3 \%$ of the clones were indicated as positive for anti-CA125, while $3 / 125(2.4 \%)$ of them displayed an OD value above 1,2. The 3 stable hybridoma cell lines, designated as A1, $\mathrm{H} 1$ and $\mathrm{H} 3$ were obtained and subcloned next three times to obtain the most high-producing stable cell lines. Results from final ELISA indicated that supernatant of the A1 clone attained about $90 \%$ positive for anti-CA125, whereas supernatants of the $\mathrm{H} 1$ and $\mathrm{H} 3$ clones were about $40 \%$ and $50 \%$ positive for antiCA125, respectively. Therefore, the A1 clone was selected for CA125 mAb production.

\section{Detection of CA125 mAb by flow cytometry}

The three stable clones were also examined for CA125 expression by flow cytometry technique using FACSAria Fusion. PBMCs (used as negative control) and OVCAR-3 cells were stained with mAbs produced by the 3 stable clones. As shown in Fig. 2A-B, CA125 mAb from A1 clone was more specific to CA125 antigen present in OVCAR -3 cells than that from $\mathrm{H} 1$ or $\mathrm{H} 3$ clone, indicating that the A1 clone was the best candidate to produce anti-CA125 mAb.

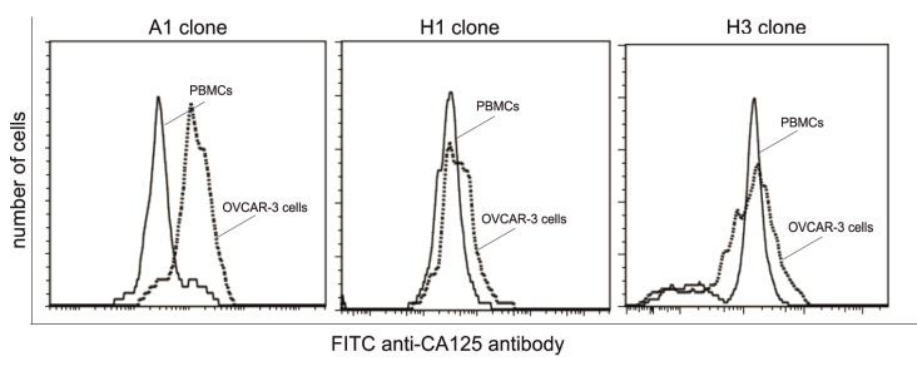

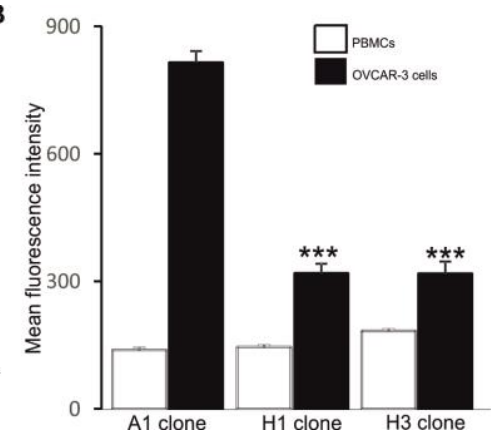

Figure 2. CA125 expression by flow cytometry analysis

A. Representative FACS histograms depicting CA125 expression in PBMCs or OVCAR-3 cells, which are stained from $\mathrm{mAbs}$ secreted by A1, H1 and $\mathrm{H} 3$ clones. B. Arithmetic means \pm SEM $(n=3)$ of CA125 expression in PBMCs or OVCAR-3 cells, which are stained from mAbs secreted by $\mathrm{A} 1, \mathrm{H} 1$ and $\mathrm{H} 3$ clones. $* * * \mathrm{p}<0.001$ indicates significant difference from CA125 $\mathrm{mAb}$ by A1 clone (ANOVA). 


\section{Isotype determination}

To determine isotypes of CA125 mAb released from A1 hybridoma cell line, we conducted experiments to examine all markers including $\operatorname{IgG} 1, \operatorname{IgG} 2 \mathrm{a}, \operatorname{IgG} 2 \mathrm{~b}, \operatorname{IgG} 3, \operatorname{Ig} \mathrm{A}$, and IgM, Kappa and Lambda light chains by
ELISA. The results in Fig. 3A-3B, OD values of IgG1 and Kappa light chain were 1.875 and 1.746 , respectively with other markers having their OD values less than 0.2 . The evidence indicated that the isotype of the obtained $\mathrm{mAb}$ was specific IgG1 and Kappa light chain.
A

\begin{tabular}{|c|c|}
\hline Dilution & Mean optical density \\
\hline IgG1 & $1.8325 \pm 0.04$ \\
\hline IgG2a & $0.1525 \pm 0.003$ \\
\hline IgG2b & $0.1705 \pm 0.001$ \\
\hline IgG3 & $0.147 \pm 0.002$ \\
\hline IgA & $0.163 \pm 0.004$ \\
\hline IgM & $0.173 \pm 0.002$ \\
\hline Kappa & $1.783 \pm 0.0037$ \\
\hline Lambda & $0.1745 \pm 0.0005$ \\
\hline
\end{tabular}

B

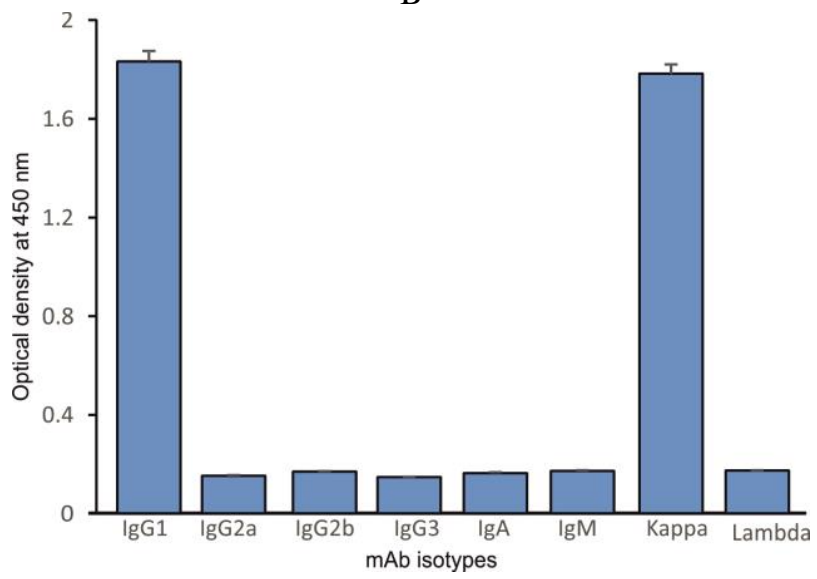

Figure 3. Determination of isotype of obtained mAb including its classes and subclasses by ELISA

Serum CA125 level in ovarian and breast cancer patients

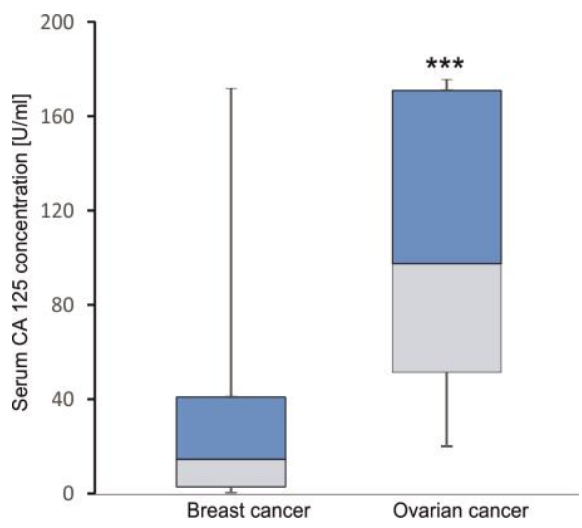

Figure 4. Serum CA125 level in ovarian and breast cancer patients

Next, we identified CA-125 content in sera of BC and OC patients by ELISA. The $\mathrm{CA} 125 \mathrm{mAb}$ was used as a capture reagent for ELISA. The results were monitored by commercial Human CA125 ELISA kit (Thermo). The results indicated that the serum CA-125 profile was different between the two patient groups. Percentages of breast and ovarian cancer patients with CA125 level $\geq$ cutoff value of $35 \mathrm{U} / \mathrm{mL}$ were $31,5 \%$ or $84,6 \%$, respectively (Figure 4). The results are consistent with a previous study that CA125 level is elevated above $35 \mathrm{U} / \mathrm{mL}$ in about $82 \%$ of women with epithelial OC (Bast et al., 1983). However, level of CA125 is also increased in leukemia patients (Birgen et al., 2005), especially in acute lymphoblatic leukemia (unpublished data), suggesting that CA125 would be one of the specific markers for early diagnosis of multiple cancers.

Arithmetic means \pm SEM $(n=13-16)$ of CA125 concentration in ovarian and breast cancer patients. $* * * \mathrm{p}<0.001$ indicates significant difference from breast cancer patients (unpaired $t$-test).

\section{DISCUSSION}

Detection of CA125 level in sera of OC and $\mathrm{BC}$ patients by ELISA technique is non time-consuming, inexpensive and suitable for all Vietnameses people. It is necessary to examine patients for early diagnosis of OC 
and $\mathrm{BC}$ and to improve the patients' outcome. There are multiple studies on biological techniques including ELISA to determine CA125 level (Gaetje et al., 2002; Felder et al., 2014). In this study we generated CA125specific $\mathrm{mAb}$ for developing a new in-house ELISA kit. Detection of the serum CA125 level in patients with $\mathrm{OC}$ and $\mathrm{BC}$ using the generated $\mathrm{mAb}$ were similar to that using the commercial Human CA125 ELISA kit of, indicating that the $\mathrm{mAb}$ from $\mathrm{A} 1$ clone by our group was specific binding to the CA125 antigen and could be used for orther purposes such as immunofluorescence, western blotting and Elispot for future researches.

CA125 is known as a main biomarker for predicting OC growth and metastasis (McIntosh et al., 2004). Ovarian cancer patients with higher CA125 content and persistence of high level of CA125 after the third chemotherapy are both associated with poorer survival of these patients (Cramer et al., 2010; Bottoni et al., 2015). Therefore, this biomarker is also used to monitor the response to treatment of $\mathrm{OC}$ patients. However, elevated level of CA125 is also found in BC patients, in our experiments, the percentage of $\mathrm{BC}$ patients with $\geq 35 \mathrm{U} / \mathrm{mL}$ serum CA125 level was $31.5 \%$, much less than that of OC patients $(84.6 \%)$. Our results are consistent with other studies, showing that this biomarker is more effective in predicting the development and stage of OC as well as assessment of therapeutic response of this disease (Gaetje et al., 2002; McIntosh et al., 2004).

A recent study reported that while CA125 level alone is not enough to identify BC risk, but a combination of enhanced expressions of all CA125, CA15-3 and CEA markers could be (Zhao et al., 2016). In addition, BC and OC patients have several common genetic features such as the pathogenic variants in BRCAl and $B R C A 2$ genes (Ford et al., 1998), which could cause elevated CA125 level in BC patients. Another investigation also suggested that families of $\mathrm{BC}$ and $\mathrm{OC}$ patients carrying $B R C A$ mutations should have their serum CA125 level examined for early detection of these disease (Vasen et al., 2005).
In conclusion, the mouse anti-human CA125 mAb generated in our lab was specific binding to CA125 antigen and used as the capture antibody in sandwich ELISA system served for early diagnosis as well as monitoring therapeutic response in OC patients.

Acknowledgements: This research is funded by $\mathrm{KC10} / 16-20$ program, the Ministry of Science and Technology, under grant number KC.10.DA06/16-20.

\section{REFERENCES}

Bast R. C., Jr., Klug T. L., St John E., Jenison E., Niloff J. M., Lazarus H., Berkowitz R. S., Leavitt T., Griffiths C. T., Parker L., Zurawski V. R., Jr., Knapp R. C., 1983. A radioimmunoassay using a monoclonal antibody to monitor the course of epithelial ovarian cancer. $N$ Engl $J$ Med, 309: 883-887.

Birgen D., Ertem U., Duru F., Sahin G., Yuksek N., Bozkurt C., Karacan C. D., Aksoy C., 2005. Serum Ca 125 levels in children with acute leukemia and lymphoma. Leuk Lymphoma, 46: 1177-1181.

Bottoni P., Scatena R., 2015. The Role of CA 125 as Tumor Marker: Biochemical and Clinical Aspects. Adv Exp Med Biol, 867: 229-244.

Coward J. I., Middleton K., Murphy F., 2015. New perspectives on targeted therapy in ovarian cancer. Int J Womens Health, 7: 189-203.

Cramer D. W., Vitonis A. F., Welch W. R., Terry K. L., Goodman A., Rueda B. R., Berkowitz R. S., 2010. Correlates of the preoperative level of CA125 at presentation of ovarian cancer. Gynecol Oncol, 119: 462-468.

Felder M., Kapur A., Gonzalez-Bosquet J., Horibata S., Heintz J., Albrecht R., Fass L., Kaur J., Hu K., Shojaei H., Whelan R. J., Patankar M. S., 2014. MUC16 (CA125): tumor biomarker to cancer therapy, a work in progress. Mol Cancer, 13: 129.

Ford D., Easton D. F., Stratton M., Narod S., Goldgar D., Devilee P., Bishop D. T., 
Weber B., Lenoir G., Chang-Claude J., Sobol H., Teare M. D., Struewing J., Arason A., Scherneck S., Peto J., Rebbeck T. R., Tonin P., Neuhausen S., Barkardottir R., Eyfjord J., Lynch H., Ponder B. A., Gayther S. A., ZeladaHedman M., 1998. Genetic heterogeneity and penetrance analysis of the BRCA1 and BRCA2 genes in breast cancer families. The Breast Cancer Linkage Consortium. Am J Hum Genet, 62: 676-689.

Gaetje R., Winnekendonk D. W., Ahr A., Kaufmann M., 2002. Ovarian cancer antigen CA 125 influences adhesion of human and mammalian cell lines in vitro. Clin Exp Obstet Gynecol, 29: 34-36.

Kohler G., Milstein C., 1975. Continuous cultures of fused cells secreting antibody of predefined specificity. Nature, 256: 495-497.

Kohler G., Milstein C., 1992. Continuous cultures of fused cells secreting antibody of predefined specificity. 1975. Biotechnology, 24: 524-526.

Libson S., Lippman M., 2014. A review of clinical aspects of breast cancer. Int Rev Psychiatry, 26: 4-15.

McIntosh M. W., Drescher C., Karlan B., Scholler N., Urban N., Hellstrom K. E., Hellstrom I., 2004. Combining CA 125 and SMR serum markers for diagnosis and early detection of ovarian carcinoma. Gynecol Oncol, 95: 9-15.

O'Brien T. J., Beard J. B., Underwood L. J., Dennis R. A., Santin A. D., York L., 2001. The CA 125 gene: an extracellular superstructure dominated by repeat sequences. Tumour Biol, 22: 348-366.

Reinartz S., Failer S., Schuell T., Wagner U., 2012. CA125 (MUC16) gene silencing suppresses growth properties of ovarian and breast cancer cells. Eur J Cancer, 48: $1558-1569$.

Senapati S., Das S., Batra S. K., 2010. Mucininteracting proteins: from function to therapeutics. Trends Biochem Sci, 35: 236-245.

Vasen H. F., Tesfay E., Boonstra H., Mourits M. J., Rutgers E., Verheyen R., Oosterwijk J., Beex L., 2005. Early detection of breast and ovarian cancer in families with BRCA mutations. Eur $J$ Cancer, 41: 549-554.

Yoo E. M., Chintalacharuvu K. R., Penichet M. L., Morrison S. L., 2002. Myeloma expression systems. J Immunol Methods, 261: 1-20.

Zhao S., Mei Y., Wang J., Zhang K., Ma R., 2016. Different Levels of CEA, CA153 and CA125 in Milk and Benign and Malignant Nipple Discharge. PLoS One, 11: e0157639. 